\title{
STUDENT-SUPERVISOR RELATIONSHIPS IN A COMPLEX SOCIETY: A DUAL NARRATIVE OF SCHOLARLY BECOMING
}

Zondiwe L. Mkhabela \& B. Liezel Frick

\section{INTRODUCTION}

Doctoral pedagogy is complex, partly due to the intricacies of the student-supervisor relationship. Manathunga (2005) refers to this relationship as taking place in a private space, which is especially true in the case of the apprenticeship approach to supervision where doctoral students often work in relative isolation with one or two supervisors.

In the South African context, this (relatively private) relationship can be even more complicated as a result of the complex historical past that still influences current learning spaces (as Daniela Gachago's first chapter in this book highlights). The racial inequalities enforced under the apartheid regime and which date even further back to colonial rule have left an indelible mark on South African education, including doctoral education. Waghid's (2015) recent reflection on his own experiences of doctoral supervision and the collection of papers edited by Aslam Fataar (2012) shed some light on this complex and complicated private space. Thus our narrative of an evolving student-supervisor relationship is not a unique one in the local South African context or even internationally (see, for example, Grant 2010a; Grant \& McKinley 2011; McKinley et al 2011; Manathunga 2013; WinchesterSeeto, Homewood, Thogersen, Jacenyik-Trawoger, Manathunga, Reid, \& Holbrook 2014). But we do not present our dual narrative as representative of these or others' stories, as each student-supervisor relationship is marked by its own particulars and peculiarities. What our story adds to the evolving South African national narrative on doctoral education is a unique perspective where both the student and the supervisor reflect on their shared so-called private learning space against the backdrop of a growing body of knowledge that sheds light on such spaces from either supervisors' or 
students' perspectives. As such, we put the spotlight on what is often the unspeakable truths marking our society and practices.

A narrative is a way in which meaning can be made from lived experience (Johnson 2006) and is by its nature socially situated (Pavlenko 2002) and contextual (Ollerenshaw \& Creswell 2002). Thus documenting these experiences is essentially autobiographical in nature. The idea of narrative space consisting of three interconnected dimensions that provide a context for any particular story (Clandinin \& Connelly 2000) was useful in making sense of our dual narrative. The three dimensions include (a) the participants, in this case our own experiences in interacting during the doctoral journey; (b) the timing of the story, how it relates to both the past and the future; and (c) the setting or locality of the story. Any story can be positioned within the space created by these three interrelated dimensions. The space creates the context within which the story is understood - by both the narrator of the story and the narrative researcher. In this case we took on both these roles as we autobiographically explored our narrated stories. Our choice of voice (Miles \& Huberman 1994) is justified in Tierney's (2002:392) notion of narrative reflexivity. Johnson and Golombek (2002:4) also note the value of reflexivity in the narrative, in that "inquiry into experience ... can be educative if it enables us to reflect on our actions and then act with foresight". Our narrative highlights the individualised and contextualised nature of doctoral education and therefore does not aim to generalise, but rather explore the complexity of the student-supervisor relationship. Our shared space was characterised by many features that created scope for an uneasy relationship, as we explain further on. However, we also explore the means by which we were able to build and sustain a productive student-supervisor relationship leading to the successful completion of the study. As such, a dual narrative such as the one presented here becomes a useful vehicle by which other students and supervisors alike may chart their own complex postgraduate journeys.

\section{A PERILOUS BUT DECISIVE START}

Grant (2010b:351) presents doctoral supervision as a "pedagogy in which our raced, classed and gendered bodies are present", and when such supervision happens across ethnic cultures (as in this case), it "becomes a pedagogical site of rich possibility as well as, at times, a place of puzzling and confronting complexity". Our joint narrative speaks to both the possibilities and complexities of such a relationship. 


\section{Liezel's narrative}

Our journey began in 2007, when a referral by a then recently retired colleague led to our paths crossing, and then ran in parallel until Zondi's graduation in March 2015. At the time, I (Liezel) had only recently completed my own PhD and was starting an academic career. I was young and inexperienced. At this stage, I had co-supervised one PhD student, but Zondi was the first student I took on as main supervisor. In addition, I am white and female. Zondi, on the other hand, had years of professional experience in the context where he wanted to conduct his study (even though he did not come into his study with a lot of research experience). He is black and male, and much older than me. Why are these personal characteristics of any importance? We came from very different places and spaces in a society where your social background, age, patriarchal traditions and ethnicity often still mark interactions between people. We were different in just about all possible respects, save our shared South African nationality and (most importantly) our mutual academic curiosity.

\section{Zondi's narrative}

In addition to the personal characteristics mentioned above, I (Zondi) brought into our student-supervisor relationship what I would now call stereotypes. Before I discuss this, I want to briefly explain why I pursued doctoral studies, my choice of university and how our student-supervisor relationship began. My doctoral studies were initially more a show of loyalty to my ancestors than a personal ambition for the highest academic accolades. I was raised by my grandmother after my mother passed on when I was nine years old. My grandmother believed in formal education as a vehicle to fight nothingness, and to build families and communities. Her wish was for my siblings and I to get a good education despite our indigent background - a wish I took seriously. My choice of university was influenced by the South African history of politics and education. Waghid (2015) argues that most non-white South African students have a bias towards achieving a qualification at a historically advantaged white university. I also developed a desire to intrude into universities that were intended for the other races and the elite of our complex South African society. My choice of university so far away from home was an attempt to break the barriers created by apartheid education, of which some are still intact today. I submitted a research proposal for consideration to the university where Liezel was employed and she was allocated to supervise my study given her expertise on adult education. I had never met Liezel before and did not know what to expect. As I was driving to our first meeting, a number of questions were running through my mind. Would she be accessible? Would she understand the narration of the problem I intended to 
investigate? Would the distance between our settings (approximately $1800 \mathrm{~km}$ ) be an obstacle or an enabler? Would she have an interest in a study that is located in a rural setting?

When I finally met her, even before we exchanged greetings, more worries crept in. I am a black South African while she is a white South African. Race was an issue to me because of the legacy of white supremacy and privilege that characterised the dayto-day life of South Africans. Waghid's (2015) argument that many black students still have feelings of mistrust and insecurity when supervised by whites held true for me at that stage. I was not sure if in this relationship there would exist what Lusted (1986) describes as a journey of production and exchange, or if my contributions would be subjected to merit or my blackness. I acknowledge that this naive thinking was confirmation of racial stereotypes that are still embedded in the psyche of most communities in South Africa due to the experiences of the past apartheid regime and colonialism as Liezel mentioned earlier.

Liezel was also much younger than me. The age difference did not worry me, but age counts in my culture (Shangaan), especially between a man and a woman in any relationship, where the man is expected to be the leader and guardian. I understood that historically most white South Africans did not have to interrupt their schooling years to fend for their families and siblings. Most of them started and finished school before they would look for employment. Age and academic progress are therefore also linked to the history of South Africa. Liezel is female and I am male. Given the history of gender inequality and stereotypes across races in South Africa, I expected that she would want to prove that women can do better than men as this was the case with my earlier interactions with women in different professional contexts. These are some of the assumptions I brought to this new student-supervisor relationship. As we talked over a cup of tea, we began to agree on communication logistics and how we would go about the work going forward. So, this first meeting got us off on a perilous but decisive start with preparations for a journey and a student-supervisor relationship that lasted six years.

Liezel: This decisive cup of tea Zondi describes was marked by a tentative search for common ground from both sides of the relationship. Looking back, I think my young and inexperienced approach as a supervisor can be described by the saying, fools rush in where angels fear to tread. I was not immune to the stereotypes Zondi described. I also wondered whether he, as an older black man, would accept my guidance and critique as his supervisor. Would he judge my potential scholarly contribution to his work based on my appearance and background? Did I know enough about his study topic and context in order to give sound advice? I remember 
making a conscious decision at that time: to directly address the obvious things that could become issues in our student-supervisor relationship, and to be unequivocal about the basis from which I worked. If he did not like it, he could still decide to study somewhere else. So I asked Zondi directly whether he had a problem with me being a young, white female person supervising his study. I also told him that though I understood that each study and student made their own demands on a supervisor, I did not discriminate when it came to quality of work - I expected the same standard of academic engagement from each of my students, no matter who they were. I had no idea what effect this forthright approach might have had on him at the time.

Zondi: Liezel's forthright style unsettled me, especially her bold stance on quality of work and the hard work she expected from her students. I felt intimidated and I began to wonder if I would be able to meet her expectations. I was, however, reassured when she said that she was looking forward to learn from me as well, especially my culture and language. I felt at ease and began my first steps in building the relationship. Lusted (1986) claims that the supervisor, the student and the knowledge produced are bound together in a pedagogical relationship and that all three these agencies change as a result of this relationship. But at the same time, there is an unequal power relation at play in this relationship (Foucault 1986), based on class position, educational biography, familiarity and competence with disciplines and ideas, differences in cultural expectations, social experience, linguistic structures, as well as confidence, commitment and energy (Lusted 1986:5), as is evident from our dual narrative presented here. Thus knowledge production requires "deep processes that get under and into the skin, assembling psycho-social dynamics of struggle, submission and subjectification" (Green 2005:151). It was therefore essential for both of us to get to know each other and our respective contexts if we were to make sense of our joint doctoral venture.

\section{GETTING TO KNOW EACH OTHER'S CONTEXTS}

Liezel's commitment that she was prepared to learn from me as well was put to test when I sent her an email after I received her comments on my proposal. It was written in my language (Shangaan) with English interpretations. The email read as follows:

Eka Liezel (Dear Liezel). Inkomu nhlamulo ndzi yi kumile (Thanks for your response I received). Inkomu, salakahle (Thanks, regards).

Her response was:

Eka Zondi. Inkomu for your revised proposal and thanks for the improvements. Inkomu, Liezel. 
Her use of "inkomu for your revised proposal" in the email was an indication to me that she was prepared to learn my language. I must confess that I did not do enough to teach her because after six years she could only greet and perhaps say goodbye in my language. My preoccupation with the study and the geographical distance between us are probably the reasons why I never taught her more. But she appreciated my effort, and her keen interest motivated me as I knew that her comments would ensure my progress.

Barbara Grant (2010b:351) eloquently points out that the complexity of both supervision and culture often go unrecognised in institutional conceptualisations of doctoral supervision:

Supervision is cast as a mainly cognitive undertaking between rational, disembodied minds, in which the dominance of western knowledge systems is rarely acknowledged or challenged ...

My (Liezel's) background in adult education sensitised me to the importance of recognising students' prior knowledge and experience, as well as honouring who they are as people. Looking back, I can now see that we came from completely different epistemic and ontological positions. I had been schooled in a predominantly western epistemic tradition, putting me in a vastly different ontological position than Zondi. Mbembe (2015) claims that such western traditions often rest on a divide between mind and world, or reason and nature, where knowledge becomes divorced from context. Given our situation, there was much room for a kind of colonised scholarship where the powerful knower renders the non-western knowledge invisible. I needed Zondi to trust my scholarly judgement, but at the same time I had to own up that I did not know everything, least of all his epistemic and ontological background and current context. Making a small effort to cross the language barrier was an attempt at crossing a much larger cultural and epistemic divide.

The next year, I (Zondi) received confirmation that the university accepted my proposal. I was allowed to register as a PhD student, and a senior professor was appointed as co-supervisor with Liezel as my main supervisor. Next, I had to complete the first chapter of my thesis. This was challenging, as I had to lay the foundation that would guide the entire study. I visited the university where I met with my supervisors. It was my first experience in an environment where academics sat with me around a table as if I were their equal. I felt somewhat intimidated, and as I presented my ideas, it became clear that the journey would not be an easy one. Every single statement I made had to be accounted for. At some point the co-supervisor asked me if I were a politician. I was unsettled by this question. Did he think my proposal was a political presentation that would not meet academic standards? But Liezel 
kept probing into my presentation, which forced me to be more natural in the way I presented my ideas.

Fataar (2012:14) refers to what Zondi must have experienced as "the shifting identity of these students as they navigate the complex personal identity terrain involved in the process of developing a credible doctoral proposal". Zondi had to learn a whole new discourse that had not previously been part of his narrative, despite having successfully completed a Master's degree. Fataar (2012) refers to this notion as a pedagogy of supervision that requires a capital alignment between the student's life world and that of the university (where the supervisor often becomes the face of the university). The supervisory relationship created the space where Zondi could test his ideas, take risks, make mistakes, invent and reinvent knowledge, but I (Liezel) needed to earn his trust so he would have the confidence and courage to do so. My colleague and I also had to model what it meant being (responsible) scholars, which was not always easy in my case as I had only started on my own academic career. Green (2005) furthermore warns that doctoral pedagogy is as much about identity production as it is about knowledge production. I realised quite early on in the process that I would be doing Zondi a disservice if I tried cloning my own research identity in him - he needed to develop his own voice. The Socratic method - which Zondi refers to as probing (see Frick, Albertyn \& Rutgers 2010) - helped me to get clarity on Zondi's ideas, so that I could guide him to own his intellectual project without me providing all the answers. I (Liezel) agree with Lin and Cranton (2005) that the transformative process that happens during a student's identity shift from being a scholarship student to becoming a responsible scholar is not easy or fast, and that it requires a gradual epistemic induction (Hugo 2009). In this case, it required a dual epistemic induction - Zondi needed to become eloquent in the dominant discourses on this chosen topic and research approach, whereas I needed to find ways to help him incorporate the co-present non-western knowledge systems that both Zondi and the nature of his study brought to our joint intellectual project.

When I next met with Liezel, I (Zondi) had lunch with her and her husband, who happened to know the area I come from. He was also in the process of completing his $\mathrm{PhD}$. He gave me a few pointers, including how I could secure funding for my studies, as I had no financial support for my tuition. He linked me up with his friend, a businessman from my area, who provided me with funding for two academic years. Given the contextual complexity that marks our dual narrative, as described in the previous section, our student-supervisor relationship was evolving into the kind of scholarly friendship Waghid (2006) describes. 
In the same year, I experienced a major setback. I was suspended from work, which affected the prospects of continuing with my studies as my work environment also formed my study site. I broke the news to Liezel. Although she was shocked, she surprisingly did not panic. She suggested that we take the study elsewhere. Her forward-looking attitude and the suggestion to take the study elsewhere inspired me to continue. We focussed on a local municipality that was also rural and shared the same social features as my initial study site. While we were initially granted permission to continue after Liezel and I met with the municipality officials and conducted a site visit within the affected rural area, the permission was subsequently withdrawn. It felt as if the study was doomed. I had to inform Liezel of these unpleasant developments hoping that we would help me find a way out of this mess. Effectively, I had lost a full year of my studies.

Later that year, a "not guilty" verdict was passed reinstating me retrospectively and I was granted permission to continue with my study at the original study site. I communicated these developments to Liezel, who had not lost hope that the study would continue. At this stage it was clear to both of us that we needed to work speedily given that we had already lost almost two years of study time. At least now I was allowed to do my study activities at work during working hours. The local authorities were keen to help me make up for the lost study time. I was also allowed unlimited internet access which facilitated my everyday contact with Liezel. This is evident in the numerous emails Liezel and I exchanged over the six years. Over the course of my study, Liezel visited me three times and I visited her four times at the university. These face-to-face-meetings were indispensable in making headway.

\section{MAKING HEADWAY}

In the midst of my studies, I (Zondi) remember discussions about my literature chapter. Reading created opportunities for constant communication between us, as everything had to be scrutinised, verified and approved. This process of managing progress was rigorous. It meant a lot of back and forth communication and required that we agreed before moving to the next step. At first I was not comfortable with the slow progress until I developed a habit of always going back to what I wrote before sending it to Liezel. This habit assisted me because when I was busy with one chapter, Liezel already looked at the chapter in relation to all the chapters that would follow. By the time I got to the next chapter, I already knew what was expected. We agreed that before going to the next chapter, we had to determine whether our work met the expectations of a doctorate. Liezel was very strict on standards. In my mind, this is what defined our student-supervisor relationship. 
At a specific point during the study, an international expert related to the field of my study visited the university. Liezel invited me to a symposium featuring this expert. I had the privilege of meeting with him and we had discussions around my topic. Although his area of specialisation was slightly different, he gave me a better understanding of my topic in different contexts. Our discussions shaped the conceptualisation of my own study. He also donated his book to me, which gave me even more insights and was influential in conceptualising the theoretical framework for my study.

During our first meeting after I got reinstated, Liezel and I outlined a progress plan that I had to follow and it became evident that we were under enormous pressure to conclude the study. Liezel proposed timelines, but by mid-year it was evident that I needed more time to collect data. Liezel and I communicated on every little bit of progress made, and thus could jointly revisit our initial targets. As I drew closer to concluding the study, the municipality where I conducted my study was placed under administration (which meant it was declared bankrupt and placed under curatorship). This development had implications for my study. I informed Liezel about these developments. We agreed that we needed to integrate these developments into my study. This meant that I had to run additional interviews and rework the sample and analysis. It also meant that we had to allow more time for the study, but we were resolute that quality would not be compromised. We agreed to take more time and have a product both of us could be proud of. I had developed the habit of working on the dissertation like it was a lifetime journey. Sometimes I would forget that I needed to graduate. I remember that even after I had integrated the administration period, Liezel continued to refer me to yet more reading sources to update the literature I used.

As we drew closer to submitting the dissertation, the email exchanges increased. Liezel advised me to get a professional editor for the dissertation. Upon receiving her message, it dawned on me that we were nearing the end of our joint journey. I sent the edited dissertation to Liezel, to which she replied, "I shall work through it and see if any final changes are necessary". Quite clearly, Liezel was prepared to work through the dissertation until the last minute. This was confirmation of her commitment to quality when it came to academic work. When she finally said, "Maybe it's time we allow the chick to try out her own wings" (which meant it is time to release our work for external examination), I had mixed feelings and many questions. Is the work good enough for examination? Did I clarify the context of the study enough for the examiners to understand? Is the study of the quality expected for a doctorate? The time we spent with the document and the amount of work we put in, reassured me. Maybe the human factor was responsible for my feelings of discomfort. Although I 
developed a lot of trust in our work over the years, I was not comfortable having our work reviewed by individuals who were not part of our journey.

It took more than nine weeks for the results to come. Finally, I received an email from Liezel that read:

It is good to be a carrier of good news on a Monday morning! We have received all your reports, and based on their feedback the oral examination will go ahead... In general the three reports are quite positive (congratulations).

My response to the message was:

I'm over the moon and ready for the oral exam.

Contrary to the message, I was anxious and confused, not knowing what questions the examiners were going to ask.

\section{THE ORAL EXAMINATION AND GRADUATION}

I was invited to the university for the oral examination. Liezel advised me to arrive a day before to allow time to prepare. On the day of the oral examination Liezel, the co-supervisor and I had a preparatory session. Liezel and the co-supervisor took me through the expected process and tried to reassure me, as I was very tense. They advised me not to give too much detail, to avoid volunteering information, and not to argue with examiners. This advice scared me even more, because I got the impression that examiners can be irritable and authoritative. After the session with my supervisors, we took a break. When we came back for the examination three hours later, the three of us were equally anxious. The oral examination took more than two hours. My supervisors were only allowed to observe. This arrangement put a lot pressure on me because I was worried that I would not represent my mentors well. When the examination was concluded, it was evident from the examiners' comments that it was an outright pass. This brought to conclusion a long journey, well travelled, and it was time to prepare for graduation.

The same evening Liezel introduced me to her Master's students. For the first time I learned how much she valued me, and I was extremely humbled. The day was concluded festively when Liezel and her husband took me out for supper the same way they did when I first became her student in 2008.

The graduation was an experience of a lifetime. It dawned on me (Zondi) that I was about to achieve the one thing I promised my ancestors. I felt excited about becoming a doctor but also disappointed because my grandmother, to whom I owed the drive for the doctorate, would not be present. To make up for my grandmother's 
absence, I invited her eldest son and my uncle to attend the ceremony. I believe, as Liezel pointed out during the graduation ceremony, that "the ancestors are pleased with this PhD award" and that my grandmother was happy with her son standing in for her.

Our joint journey over six years taught us many lessons. We summarise these under the following headings: understand each other's contexts, mutual kindness as a basis for supervision, the need for compassionate rigour, and the necessity of consulting experts along the way.

\section{Understanding each other's contexts}

We came into the supervisory relationship from vastly different places and spaces, as is evident from our dual narrative. Looking back, we realise how fragile the basis was on which our joint knowledge venture was built. We also realise the importance of understanding and respecting each other's contexts in mediating such fragile student-supervisor relationships. Meeting face-to-face on a regular basis at either the university or the study site gave us each the opportunity to understand the other's contexts. These meetings were essential in not only situating the study from both contextual and scholarly perspectives, but also building our mutual trust and understanding. It gave us the opportunity to get to know each other as people, not just disembodied knowledge workers. In previous work, I (Frick 2011) argued that doctoral becoming requires an alignment between how students view themselves in relation to the research process of becoming a scholar (ontology), how they relate to different forms of knowledge (epistemology), how they obtain and create such knowledge (methodology), and how they frame their interests in terms of their values and ethics within the discipline (axiology). This line of argument positions doctoral becoming as an ontological, epistemological, methodological and axiological concern in which supervisors need to help students' transformation to doctorateness (as described by Wellington 2013). But it is not only the student who is transformed - supervisors also need to shift their ontological, epistemological, methodological and axiological positions when they are faced with students who come from nontraditional knowledge systems.

\section{Building mutual kindness and trust}

Clegg and Rowland (2010) argue that kindness is one of the necessary but often unremarked aspects of good teaching. However, acts of kindness may also paradoxically be construed as misjudged or harmful to others. Kindness cannot be regulated or prescribed, but forms one of the core aspects of what makes us human 
(and sometimes it is kindness that makes us carry on despite setbacks or misfortune). We would argue that mutual kindness is one of the core aspects that defined our student-supervisor relationship, and that kindness built mutual trust that facilitated our eventual progress. A mutual show of kindness provided a strong foundation for the otherwise rigorous and sometimes harsh academic critique that characterises doctoral supervisory discourses.

\section{No compromises on quality: the role of compassionate rigour in doctoral education}

Doctoral studies are not examined by the supervisors in the South African context, but supervisors play a key role in ensuring that such studies meet the demands of being academically rigorous and making an original contribution. Thus, while mutual kindness and trust lay the foundation for a respectful and humane student-supervisor relationship, it was equally important that the scholarly quality of the work itself not be compromised in any way. Ensuring quality of the doctoral contribution sometimes calls for rigorous debate and a continuous re-interrogation of the merit of the work. Such responses to scholarly work need to be rigorous by necessity, but at the same time compassionate (Manathunga 2005). Compassionate rigour furthermore allows for a more complex understanding of doctorateness, as Wellington (2013) suggests. Such an understanding would allow non-dominant ontological and epistemological positions to enter the doctoral discourse, and make the learning experience richer for both student and supervisor.

\section{Utilising experts}

There were other contributors who played a meaningful role in the study. The first was the co-supervisor in this study, who provided expert advice when called upon, and gave us the space to explore the details of the study in our own time. Cosupervision has the potential to complicate the student-supervisor relationship, but it also has the potential to add value - especially if one supervisor is a novice. In our experience, clarifying student and supervisor role expectations upfront is key to building a strong team. Universities further have many support services that may be useful even to students who complete their studies at a distance. In this case, the subject librarian was a key role player in making sources available in a timely manner. Consulting with international experts and scholars when the opportunity arose was also influential in taking the study forward. Such experts may provide different perspectives and insights that can facilitate progress. Our experience has taught us to utilise expertise and support where appropriate and where available to our benefit. 


\section{CONCLUSION: THE DUAL NARRATIVE AS AN ON-GOING STORY}

Writing a dual narrative about our shared student-supervisor relationship has been a difficult but rewarding endeavour. We had to delve deep within ourselves and into our shared experiences to make sense of our dual narrative, and how it could sensibly be reflected against existing scholarship on doctoral pedagogy. The mutual understanding, trust, kindness and compassionate rigour we built up over a period of more than six years enabled us to approach this task with both sensitivity and academic rigour. We were sometimes surprised by each other's take on our shared story, but agreed that honesty needed to be the hallmark of the contribution we aim to make. We agree that what you have read is a true representation of our shared story.

The purpose of this dual narrative has been to provide a balanced account of how a student-supervisor relationship develops in a complex society such as that of South Africa. We have shown that such a relationship does not develop in isolation of societal factors - neither students nor supervisors can afford to ignore each other's ontological and epistemological positions during a study. We have argued that understanding each other's contexts, building mutual kindness and trust, excepting no compromises on quality through compassionate rigour, and utilising experts when appropriate helped to solidify what started out as a fragile student-supervisor relationship. What postgraduate students and supervisors may draw from this dual narrative is that social factors including the context in which studies are conducted may influence their outcomes. There is, however, room for further interrogation of each of these aspects from both supervisors' and students' perspectives in a (South) African context.

\section{REFERENCES}

Clandinin, D. J. \& Connelly, F. M. (2000). Narrative inquiry: Experience and story in qualitative research. San Francisco, USA: Jossey-Bass.

Clegg, S., \& Rowland, S. (2010). Kindness in pedagogical practice and academic life. British Journal of Sociology of Education, 37 (6), 719-735. http://dx.doi.org/10.1080/01425692.2010.515102

Fataar, A. (Ed.). (2012). Debating thesis supervision. Stellenbosch, South Africa: AFRICAN SUN MeDIA.

Foucault, M. (1986). Disciplinary power and subjection. Power, 229-242.

Frick, B. L. (201 1). Facilitating creativity in doctoral education: A resource for supervisors. In A. Lee \& V. Mallan (Eds.). Connecting the local, regional and global in doctoral education (pp. 123-137). Serdang, Malaysia: Universiti Putra Malaysia Press. 


\section{POSTGRADUATE STUDY IN SOUTH AFRICA}

Frick, B. L., Albertyn, R. M., \& Rutgers, L. (2010). The Socratic Method: Exploring theories underlying critical questioning as a pathway in student independence. Acta Academica, Supplementum 1:75-102.

Grant, B. (2010a). Challenging issues: Doctoral supervision in post-colonial sites. Acta Academica, Supplementum 1 (2010):103-129.

Grant, B. M. (2010b). The limits of 'teaching and learning': Indigenous students and doctoral supervision. Teaching in Higher Education, 15(5), 505-517. http://dx.doi.org/10.1080/13562517.2010.491903

Grant, B., \& McKinley, E. (2011). Colouring the pedagogy of doctoral supervision: Considering supervisor, student and knowledge through the lens of indigeneity. Innovations in Education and Teaching International, 48(4):377-386. http://dx.doi.org/10.1080/14703297.2011.617087

Green, B. (2005). Unfinished business: Subjectivity and supervision. Higher Education Research and Development, 24(2):151-163. http://dx.doi.org/10.1080/07294360500062953

Holbrook, A. (2014). Doctoral supervision in a cross-cultural context: Issues affecting supervisors and candidates. Higher Education Research \& Development, 33(3):610-626. http://dx.doi.org/10.1080/07294360.2013.841648

Hugo, W. (2009). Spiralling reference. A case study of apprenticeship into an academic community of practice. South African Journal of Higher Education, 23(4):703-721.

Johnson, K. E. (2006). The sociocultural turn and its challenges for second language teacher education. TESOL Quarterly, 40(1):235-257. http://dx.doi.org/10.2307/40264518

Johnson, K. E., \& Golombek, P. R. (Eds.) (2002). Teachers' narrative inquiry as professional development. Cambridge, UK: Cambridge University Press.

Lin, L., \& Cranton, P. (2005). From scholarship student to responsible scholar: A transformative process. Teaching in Higher Education, 10(4):447-459. http://dx.doi.org/10.1080/13562510500239026

Lusted, D. (1986). Why pedagogy? Screen, 27(5):2-16.

Manathunga, C. (2013). Culture as a place of thought. In A-C. R. Engels-Schwarzpaul \& M. A. Peters (Eds.). Of other thoughts: Non-traditional ways to the doctorate (pp. 67-82). Rotterdam, Netherlands: Sense Publishers. http://dx.doi.org/10.1007/978-94-6209-3171

Manathunga, C. (2009). Supervision as a contested space: A response. Teaching in Higher Education, 14(3):341-345. http://dx.doi.org/10.1080/13562510902990242

Manathunga, C. (2005). The development of research supervision: "Turning a light on a private space". International Journal for Academic Development, 10(1):17-30. http://dx.doi.org/10.1080/13601440500099977

Mbembe, A. (2015). Decolonizing knowledge and the question of the archive. Retrieved from http://wiser.wits.ac.za/system/files/Achille\%20Mbembe\%20-\%20Decolonizing\%20 Knowledge\%20and\%20the\%20Question\%20of\%20the\%20Archive.pdf 
McKinley, E., Grant, B., Middleton, S., Irwin, K., \& Williams, L. R. T. (2011). Working at the interface: Indigenous students' experience of undertaking doctoral studies in Aotearoa New Zealand. Equity and Excellence in Education, 44(1):115-132. http://dx.doi.org/10.1080/10665684.2010.540972

Miles, M. B. \& Huberman, A. M. (1994). Qualitative data analysis: An expanded sourcebook. Thousand Oaks, USA: Sage Publications.

Ollerenshaw, J., \& Creswell, J. (2002). Narrative research: A comparison of two restorying data analysis approaches. Qualitative Inquiry, 8(3):329-347. http://dx.doi.org/10.1177/10778004008003008

Pavlenko, A. (2002). Narrative study: Whose story is it anyway? TESOL Quarterly, 36(2):213-218. http://dx.doi.org/10.2307/3588332

Tierney, W. G. (2002). Getting real: Representing reality. International Journal of Qualitative Studies in Education, 15(4):385-398. http://dx.doi.org/10.1080/09518390210145444

Waghid, Y. (2006). Reclaiming freedom and friendship through postgraduate student supervision. Teaching in Higher Education, 11 (4):427-439. http://dx.doi.org/10.1080/13562510600874185

Waghid, Y. (2015). Dancing with doctoral encounters: Democratic education in motion. Stellenbosch, South Africa: AFRICAN SUN MeDIA.

Wellington, J. (2013). Searching for 'doctorateness'. Studies in Higher Education, 38(10): 1490-1503. http://dx.doi.org/10.1080/03075079.2011.634901

Winchester-Seeto, T., Homewood, J., Thogersen, J., Jacenyik-Trawoger, C., Manathunga, C., Reid, A., \& Holbrook, A. (2014). Doctoral supervision in a cross-cultural context: Issues affecting supervisors and candidates. Higher Education Research \& Development, 33(3):610-626. 